\title{
Discriminating aging and protein-to-fat ratio in Cheddar cheese using sensory analysis and a potentiometric electronic tongue
}

\author{
Jackie B. Lipkowitz, Carolyn F. Ross, ${ }^{1}$ Charles Diako, and Denise M. Smith \\ School of Food Science, Washington State University, Pullman 99164
}

\begin{abstract}
The objectives of this study were to evaluate the flavor and taste attributes of full-fat Cheddar cheeses with different protein-to-fat ratios (PFR) over aging time using a descriptive sensory analysis panel and a consumer panel, and to correlate these attributes with instrumental parameters obtained by the potentiometric electronic tongue. Three Cheddar cheese formulations (PFR of 0.74, 0.85, and 1.01) were produced in triplicate and composition was verified. Cheese was aged at $7.2^{\circ} \mathrm{C}$ and evaluated at $2,5,8,10,11$, and 12 mo by a trained panel $(\mathrm{n}=10)$ for 8 flavor and 5 taste attributes and using an electronic tongue for 7 nonvolatile taste attributes. Cheese aged for 12 mo was also evaluated by a consumer sensory panel for liking and intensity attributes. Principal component analysis was performed to discriminate cheese based on aging time and PFR, whereas correlation between sensory and instrumental attributes was assessed using partial least squares regression. Descriptive sensory analysis of flavor and taste attributes differentiated Cheddar cheeses over aging time, but not among PFR formulations. The electronic tongue distinguished changes among cheese samples due to PFR formulation and aging time. The electronic tongue proved successful in characterizing the nonvolatile flavor components in Cheddar cheese and correlated with taste perceptions measured by descriptive sensory analysis. Consumer evaluations showed distinctive attribute profiles for the 3 PFR Cheddar cheese formulations. Overall, higher fat content was associated with increased flavor intensities in Cheddar cheese and drove consumer acceptability and purchase intent ratings. The electronic tongue detected smaller changes in tastes (bitter, metallic, salty, sour, spicy, sweet, and umami) of the 3 PFR formulations over time when compared with the trained panelists, who detected no differences, suggesting that the electronic tongue may be more sensitive to tastants
\end{abstract}

Received September 12, 2017.

Accepted November 17, 2017.

${ }^{1}$ Corresponding author: cfross@wsu.edu than humans and may have the capability for early detection or identification of problems in a batch of cheese during aging. Results suggest taste quality of cheese may be monitored using the electronic tongue with greater sensitivity than a trained panel, and may be more objective, rapid, and cost effective than human panelists.

Key words: Cheddar cheese, aging, sensory, electronic tongue

\section{INTRODUCTION}

Manufacturers of full-fat Cheddar cheese often standardize protein-to-fat ratio (PFR) in their cheese milk to manage costs and seasonal variations in milk to maintain manufacturing efficiency, batch to batch consistency, predictability of cheese yield, and quality of the final product (Rattray and Jelen, 1996; Guinee et al., 2007). For commercial full-fat Cheddar cheese, the typical PFR ranges from 0.70 to 1.15, whereas PFR for reduced- and low-fat Cheddar cheeses generally exceeds 1.3 (Banks, 2004; Guinee et al., 2007). Manufacturers may reduce the fat content to concentrations within legal specifications for full-fat Cheddar cheese to mitigate the cost of cheese milk on overall production costs; however, even small reductions in fat content may affect flavor, texture, and consumer acceptance (Drake et al., 2009). The minimum milkfat content must be at least $50 \%$ by weight of solids and the maximum moisture content cannot exceed $39 \%$ by weight to be labeled as full-fat Cheddar cheese (CFR, 2016).

Younger cheeses are characterized by cooked, milky, and whey flavors, whereas aged cheeses boast nutty, sulfur, and acidic/sour notes (Iwasawa et al., 2014). Glycolysis, proteolysis, and lipolysis during ripening break down lactose, citrate, proteins, and lipids to develop the characteristic flavors associated with Cheddar cheese, whereas fat globules may entrap flavor and taste components within the casein network, affecting the rate and amount released in the mouth during mastication (Clark et al., 2009).

Taste compounds of interest in Cheddar cheese include bitter, salty, sour, sweet, and umami. Ac- 
ids contribute to the sensation of sourness. Cheddar cheese principally contains lactic acid; however, acetic and propionic acid may also contribute to a sour taste sensation. Sodium chloride is the main contributor to salty taste. Increasing maturity and concentration and decreasing $\mathrm{pH}$ affect the apparent saltiness of a cheese (Singh and Cadwallader, 2008). Hydrolyzed peptides are responsible for many of the bitter, sour, sweet, and metallic taste sensations in Cheddar cheeses during ripening (Singh and Cadwallader, 2008). Sweet taste may also be contributed by the breakdown of lactose. Umami taste is associated with the presence of monosodium glutamate, disodium-5'-ionsine monophosphate, sodium chloride, and lactic acid (Drake et al., 2007). A higher fat content in a cheese suppresses bitter and sour tastes, whereas salty content is highly affected by aging (Yang and Vickers, 2004). A higher fat content usually leads to higher primary proteolysis in Cheddar cheese (Fenelon and Guinee, 2000), causing lower fat cheeses to develop aroma and flavor more slowly (Singh et al., 2003).

A potentiometric electronic tongue detects nonvolatile substances using nonspecific, low-selective chemical sensors within liquid matrices with cross-sensitivity (Latha and Lakshmi, 2012; Kalit et al., 2014), and may mimic human gustation. Alpha MOS (Toulouse, France) produces a common potentiometric electronic tongue, consisting of a sensor array with 7 transistors displaying different sensitivity to acids, salts, and mono-and di-saccharides to pick up bitter, metallic, salty, spicy, sour, sweet, and umami tastes (Escuder-Gilabert and Peris, 2010). Application of the electronic tongue is more objective, does not become fatigued, and after initial setup, may be less expensive and time consuming than a sensory panel for routine product evaluation (Escuder-Gilabert and Peris, 2010). Electronic tongue technology has been applied within the food and beverage industry and specifically within the dairy sector to products such as milk, yogurt, and protein hydrolysates (Hruskar et al., 2009; Li et al., 2014; Newman et al., 2014a,b); however, no studies have solely focused on taste evaluation of cheese to provide insights into the development and variation in taste during the ripening process.

Studies on reduced and low-fat concentrations in Cheddar cheese and its effects on quality parameters are plentiful, but there is a shortage of literature on the effect of altering PFR on the aroma, flavor, taste, and texture of full-fat commercial Cheddar cheese. This study followed changes in flavor and taste due to aging time and PFR of Cheddar cheese using a potentiometric electronic tongue, and descriptive and consumer sensory analysis, and correlations were determined. Our goal was to provide an overarching look at quality parameters of Cheddar cheese and the ways quality can be measured by both human subjects and instruments. In addition, this information can help Cheddar cheese manufacturers optimize the PFR of their cheese to maintain a high-quality product, while reducing costs of manufacture.

\section{MATERIALS AND METHODS}

\section{Materials}

Whole milk was obtained from Knott Dairy Center (Pullman, WA) on the day of production. Skim milk and cream were purchased from Darigold Inc. (Seattle, WA). Freeze-dried DV850 lactic starter cultures and rennet (CHY-MAX Extra) were purchased from Chr. Hansen (Milwaukee, WI), and Lactobacillus helveticus WSU19 was supplied as an adjunct culture by the Washington State University Creamery (Pullman). Morton Top Flake Topping Salt was purchased from Morton Salt Inc. (Chicago, IL). Materials for standard recipe preparation for flavor and taste evaluation included monosodium glutamate (Ajinomoto North America Inc., Fort Lee, NJ), butyric acid (Nutritional Biochemicals Corp., Cleveland, $\mathrm{OH}$ ), diacetyl, sodium chloride, citric acid, and quinine sulfate (Sigma-Aldrich, St. Louis, MO). The reference cheese (Tillamook Sharp White Cheddar, Tillamook, OR), a 4-yr aged cheese (Black Diamond Mature Reserve, Parmalat Canada, Toronto, Canada), sliced canned potatoes (Safeway Kitchens, Pleasanton, CA), whipping cream (Lucerne Foods, Boise, ID), and Hint of Salt Wheat Thins (Nabisco, East Hanover, NJ), fresh pineapple, eggs, unsalted saltines, seedless green grapes, and plastic cuspidors were purchased from a local grocery store (Pullman, WA). Cheese was served in 118-mL plastic soufflé containers (Solo, Lake Forest, IL). Electronic tongue standards, including hydrochloric acid, sodium chloride, and sodium-L-glutamate, were obtained from Alpha MOS. Ultrapure water was used for electronic tongue analysis (Millipore Corp., Billerica, MA). Chloroform and methanol met American Chemical Society grade standards; all other chemicals were reagent or analytical grade.

\section{Cheddar Cheese Production}

Whole milk was collected on the day of production, pasteurized at $72^{\circ} \mathrm{C}$ for $15 \mathrm{~s}$, cooled to $32^{\circ} \mathrm{C}$, and used immediately for cheese production. Skim milk and cream were stored for up to $4 \mathrm{~d}$ at $3.3^{\circ} \mathrm{C}$ until used. Unhomogenized whole milk, skim milk, and cream were added to horizontal cheese vats in specific ratios to achieve target PFR of $0.75,0.85$, and 1.00. Milk was heated to $32^{\circ} \mathrm{C}$ by steam in the tank jacket and 
inoculated with $0.02 \%$ DV850 starter culture (blend of L. cremoris and L. lactis) and $0.33 \%$ L. hevelticus WSU 19. Rennet (CHY-MAX Extra; 0.045\%, 650 $\mathrm{IMCU} / \mathrm{mL}$ ) was added, stirred gently for $2 \mathrm{~min}$, and the milk was allowed to coagulate for $30 \mathrm{~min}$. Once a firm set was achieved, the curd was cut and allowed to heal for $10 \mathrm{~min}$. The curd was cooked by increasing the temperature to $39^{\circ} \mathrm{C}$ for $80 \mathrm{~min}$. Vats were drained at a titratable acidity of 0.13 . Curd was cut, shaped into loaves, and cheddared until a titratable acidity of 0.46 , after which the curd was milled by hand. Morton Top Flake Topping Salt was added at 0.26, 0.25, and $0.24 \%$ to target PFR formulations of $0.75,0.85$, and 1.00 , respectively. The curd was hooped and pressed at about $400 \mathrm{kPa}$. After $1 \mathrm{~h}$, cheese was wrapped in cheesecloth and pressed for an additional $23 \mathrm{~h}$. Manufactured cheeses were vacuum sealed under about 69 $\mathrm{kPa}$ in $15.24 \mathrm{~cm}$ diameter by $5.40 \mathrm{~cm}$ height steel cans with a lacquer sealant and aged for up to $12 \mathrm{mo}$ at $7.2^{\circ} \mathrm{C}$. Each cheese formulation was manufactured in triplicate batches on consecutive days.

\section{Proximate Analysis}

Composition of each batch of Cheddar cheese was analyzed in triplicate after $7 \mathrm{~d}$ aging at $7.2^{\circ} \mathrm{C}$. Official methods were used for moisture (AOAC International, 2000; method number 990.20; 33.2.44), fat (Wehr and Frank, 2004; method number 15.083) and salt (AOAC International, 2000; method number 983.14; 33.7.09). The $\mathrm{pH}$ was measured by blending $10.0 \mathrm{~g}$ of grated cheese with $90.0 \mathrm{~mL}$ of carbon dioxide-free distilled water with an Oakton model $700 \mathrm{pH}$ meter and model WD-35801-71 combination electrode (Vernon Hills, IL). Ten grams of grated cheese was dried at $100^{\circ} \mathrm{C}$ for $24 \mathrm{~h}$, ground in a mortar and pestle, and triplicate samples from each batch were analyzed using a TruMac Carbon/Nitrogen 628 analyzer (Leco Corporation, St. Joseph, MI) and a factor of 6.38 to convert nitrogen to protein content (AOAC International, 2000; method number $992.23 ; 32.2 .02)$.

\section{Descriptive Sensory Analysis}

Sensory panelists $(\mathrm{n}=10)$ were recruited from Washington State University through electronic advertisement and word of mouth. The panel was composed of 6 women and 4 men ranging in age from 23 to 54 yr, with a mean age of $30 \mathrm{yr}$. Panelists were selected based upon 12 mo availability; no previous experience in trained sensory panels was required. All panelists indicated that they consumed cheese at least once to several times a week. The Washington State University Institutional Review Board approved the project for use of human subjects, and all trained panelists signed an informed consent form on the first day of training. Panelists received minimum background information about the study to reduce potential bias and were informed they would be evaluating Cheddar cheese over $20 \mathrm{~h}$ of training and 6 formal evaluation sessions over a 12-mo period. Panelists participated in training sessions in which they were instructed on techniques for evaluation of flavor and taste of Cheddar cheese using an established cheese sensory language with some adaptation (Drake et al., 2001; Rogers et al., 2009). Attributes and references used in this study were adapted to type of Cheddar cheese tested and panelist input. Training for all attributes was conducted through presentation of standards and assigned intensities (Table 1). Panelists received nonmonetary incentives at the completion of each training session and 3 larger nonmonetary rewards upon completion of formal evaluations throughout the study.

A 1-h training (calibration) session was conducted before each formal evaluation period for panelists to review standards and complete Feedback Calibration (Compusense Cloud, Guelph, Ontario, Canada) to realign panelists with target ranges for the reference cheese. Formal evaluations were performed in individual sensory facility booths under white lights at $2,5,8,10,11$, and 12 mo after cheese manufacture. Panelists rated the perception of attributes along a 15$\mathrm{cm}$ structured line scale, with anchors at $1.5 \mathrm{~cm}$ to indicate low and $13.5 \mathrm{~cm}$ to indicate high. Cheddar cheese was cut into $2.5-\mathrm{cm}^{3}$ cubes and 5 cubes were placed into 118-mL plastic soufflé containers with randomly generated 3-digit codes. Experimental cheeses and the standard reference cheese were evaluated by panelists in replicate, one at a time, in a completely randomized balanced design. Panelists were required to pause for at least $30 \mathrm{~s}$ between samples, during which they rinsed their palate with ambient temperature filtered water, unsalted saltine crackers, and seedless green grapes. Panelists were instructed to expectorate samples after evaluation. A 15-min break was required after the fourth sample to refresh panelists' palates and minimize fatigue. Results were collected electronically by Compusense Cloud.

\section{Electronic Tongue Analysis}

A lipid-free cheese extract was prepared to prevent damage to the potentiometric sensors of the electronic tongue. Briefly, $3.00 \pm 0.01 \mathrm{~g}$ of cheese was homogenized in $90 \mathrm{~mL}$ of $2: 1$ ( $\mathrm{vol} / \mathrm{vol}$ ) chloroform: methanol, followed by the addition of $30 \mathrm{~mL}$ of Ultrapure water, and allowed to extract for $20 \mathrm{~min}$ (Folch et al., 1957). The extract was centrifuged at 2,500 $\times g$ for 30 min at 
Table 1. Sensory flavor and taste attributes, definitions, standard references, and intensities for formal evaluation by trained panel $(\mathrm{n}=10)$ developed by Drake et al. (2001) with some modification

\begin{tabular}{|c|c|c|c|}
\hline Attribute & Definition & Standard reference & Intensity $^{1}$ \\
\hline Age & Flavor associated with age in Cheddar cheese & Aged 4-yr-old Cheddar cheese & 10.5 \\
\hline $\mathrm{FFA}^{2}$ & Aromatics associated with short-chain fatty acids & $20 \mathrm{mg} / \mathrm{kg}$ of butyric acid in water & 9.0 \\
\hline Fruity & Aromatics associated with different fruits & Fresh pineapple & 12.0 \\
\hline Milk fat & Aromatics associated with milk fat & Heavy cream & 9.0 \\
\hline \multicolumn{4}{|c|}{ 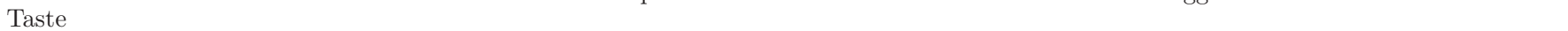 } \\
\hline Bitter & Fundamental taste sensation elicited by quinine & $0.006 \%$ quinine in water & 12.0 \\
\hline Salty & Fundamental taste sensation elicited by salts & $0.75 \%$ sodium chloride in water & 9.5 \\
\hline Sour & Fundamental taste sensation elicited by acids & $0.08 \%$ citric acid in water & 10.0 \\
\hline Sweet & Fundamental taste sensation elicited by sugars & $5 \%$ sucrose in water & 10.5 \\
\hline Umami & Chemical feeling factor elicited by certain peptides and nucleotides & $1 \%$ monosodium glutamate in water & 10.0 \\
\hline
\end{tabular}

${ }^{1}$ Assigned intensity using a 15 -cm line scale.

${ }^{2} \mathrm{FFA}=$ free fatty acid.

$22^{\circ} \mathrm{C}$. The polar upper phase was collected, filtered, and evaporated to produce $25 \mathrm{~mL}$ of extract. The extract was filtered again before electronic tongue analysis to remove any remaining particulates. Preliminary studies indicated that the chloroform: methanol extraction process removed 2 to $5 \%$ of salt from the Cheddar cheese.

Taste attributes were analyzed using an Astree II potentiometric electronic tongue (Alpha MOS) equipped with a liquid auto sampler (LS48) and 7 set \#5 sensors (bitter, metallic, salty, sour, spicy, sweet, and umami). The sensors were hydrated overnight in $25 \mathrm{~mL}$ of Ultrapure water before pre-run conditioning, calibration, and diagnostics. Standard solutions of $0.01 M$ hydrochloric acid, sodium chloride, and sodium-L-glutamate were used to prepare the system and sensors according to the manufacturer's instructions. The following parameters were used for autosampler collection: delay $=0 \mathrm{~s}$, acquisition time $=120 \mathrm{~s}$; stirring rate $=1$; and acquisition period $=1$. Between each cheese sample, the sensors were cleaned for $10 \mathrm{~s}$ in $25 \mathrm{~mL}$ of Ultrapure water. This collection method was looped 6 times for a complete run. Electronic tongue analysis was performed at $2,5,8,10,11$, and 12 mo after cheese manufacture. The reference cheese used in descriptive sensory analysis was run at each time point to link electronic tongue results using reference compensation.

\section{Consumer Sensory Evaluation}

Consumer evaluation was conducted in a single session at 12 mo after cheese manufacture using the sensory evaluation facilities at Washington State University (Pullman). Consumers $(\mathrm{n}=120)$ were recruited from the university students, staff, and faculty through electronic mail, flyers, and word of mouth. Consumers signed informed consent forms consistent with human subject approval by the Washington State University Institutional Review Board. Compusense Cloud was used to collect all responses to demographic and scoring ballot information. Cheese samples were cut into $2.5-\mathrm{cm}^{3}$ cubes and 2 cubes were dispensed into $118-\mathrm{mL}$ soufflé cups labeled with randomly generated 3-digit codes. The 3 PFR formulations were evaluated by panelists one at a time in a completely randomized balanced design. The scoring ballot included 11 liking questions, in which consumers used a 9-point hedonic scale, where $1=$ dislike extremely and $9=$ like extremely, to rate the cheeses for aged/sharp flavor, appearance, aroma, Cheddar cheese flavor, crumbliness, firmness, milky/ dairy flavor, overall flavor, overall liking, overall texture, and salty taste. Intensity of 4 attributes (aged/ sharp flavor, Cheddar cheese flavor, milky/dairy flavor, salty taste) was also scored on a 9-point scale, where $1=$ low intensity, $4.5=$ moderate intensity, and $9=$ high intensity). Consumers also rated purchase intent using a 5 -point scale, where $1=$ definitely would not purchase and $5=$ definitely would purchase. A 1-min rest was enforced between each sample to help prevent fatigue, during which consumers were instructed to cleanse their palates using ambient temperature deionized water, unsalted crackers, and seedless green grapes provided. Consumers received nonmonetary incentives at the completion of the evaluation session.

\section{Statistical Analysis}

Proximate analysis data were analyzed using Stata version 14.2 software (StataCorp, College Station, TX) using ANOVA to model main effects (compositional components, batch, replicate) and their interactions. 
Table 2. Composition of Cheddar cheeses (wet weight basis) ${ }^{1}$

\begin{tabular}{lcccccc}
\hline Item & PFR & Moisture (\%) & Fat (\%) & Protein $(\%)$ & Salt (\%) & $\mathrm{pH}$ \\
\hline LPFR & 0.74 & $37.49^{\mathrm{b}}(0.77)$ & $34.11^{\mathrm{a}}(1.14)$ & $25.23^{\mathrm{c}}(0.59)$ & $1.35^{\mathrm{b}}(0.06)$ & $4.91^{\mathrm{a}}(0.11)$ \\
MPFR & 0.85 & $38.80^{\mathrm{a}}(0.37)$ & $31.17^{\mathrm{b}}(0.87)$ & $26.47^{\mathrm{b}}(0.42)$ & $1.31^{\mathrm{b}}(0.05)$ & $4.86^{\mathrm{a}}(0.14)$ \\
HPFR & 1.01 & $38.27^{\mathrm{ab}}(1.10)$ & $27.83^{\mathrm{c}}(0.50)$ & $28.04^{\mathrm{a}}(0.26)$ & $1.42^{\mathrm{a}}(0.06)$ & $4.86^{\mathrm{a}}(0.08)$ \\
\hline
\end{tabular}

${ }^{\mathrm{a}-\mathrm{c}}$ Means within a column with different superscripts differ $(P<0.05)$.

${ }^{1} \mathrm{PFR}=$ protein-to-fat ratio; $\mathrm{LPFR}=$ low PFR; MPFR $=$ medium PFR; HPFR $=$ high PFR. All tests were performed within 1 wk after production, except salt performed after 12 mo of storage at $7.2^{\circ} \mathrm{C}$. Values in parentheses indicate SEM.

Trained panelist data were analyzed using mixed-model ANOVA with repeated measures and best-fit covariance matrix to model main effects (aging time, PFR formulation) and their interaction using SAS University Edition (version 3.7, SAS Institute Inc., Cary, NC). If results were significant, Fisher's least significant difference test was used for mean separation. Principal component analysis (PCA) showing discrimination index and discriminant analysis using leave-one-out crossvalidation were performed on electronic tongue output to discriminate and classify cheese based on age and PFR, whereas correlations with trained panel sensory evaluations were assessed using partial least squares regression using Astree AlphaSoft software (version 12.44; Alpha MOS) and XLSTAT Sensory 18.07 (Addinsoft, New York, NY). The loadings and scores from the PCA obtained from the AlphaSoft software were plotted as PCA biplot using R Base Graphics (R Core Team, 2017). Principal component analysis was also performed on descriptive sensory data using XLSTAT Sensory 18.07 (Addinsoft, New York, NY). Principal component loading factors were used to indicate attributes of primary importance on each axis if $>|0.500|$.

Consumer sensory evaluation data were analyzed using 2-way ANOVA using Stata version 14.2 software (StataCorp, College Station, TX) to model main effects (panelist, formulation, replicate) and the panelist $\times$ formulation interaction. Cluster analysis was performed using 2-way ANOVA with main effects (cluster, liking attributes) and their interactions. Fisher's least significant difference test was used for mean separation if results were significant. Correlations between consumer sensory evaluation and descriptive sensory analysis were evaluated using partial least square regression with XLSTAT Sensory 18.07 (Addinsoft).

\section{RESULTS AND DISCUSSION}

\section{Cheddar Cheese Composition}

Cheeses with PFR of $0.74,0.85$, and 1.01 were produced (Table 2) and fell within the typical commercial PFR range of 0.70 to 1.15 for full-fat Cheddar (Guinee et al., 2007). As expected, the low PFR (LPFR) of 0.74 had the highest fat content and lowest protein content $(P<0.05)$. The LPFR and medium PFR (MPFR) of 0.85 met the legal specifications for full-fat Cheddar cheese under Title 21 CFR Section 133.113 for moisture and fat content (CFR, 2016). The high PFR (HPFR) formulation of 1.01 with $45.1 \%$ fat (dry basis) did not meet the minimum specification of $50 \%$ fat (dry basis) for a full-fat cheese (CFR, 2016), but had a PFR typical for a full-fat Cheddar.

The amount of salt added during production was intentionally decreased as the target PFR was increased, as curd with higher moisture content was expected to absorb more salt (Guinee et al., 2007). Although less salt $(0.24 \%)$ was used in the HPFR formulation, it had a higher finished salt content of $1.42 \%$ than the LPFR and MPFR $(P<0.05)$. The $\mathrm{pH}$ levels of all formulations were not different $(P>0.05)$ when measured $7 \mathrm{~d}$ after manufacture, as the curd was cheddared to a titratable acidity of 0.46 . No inter-batch variation was present in moisture, fat, protein, salt, and $\mathrm{pH}$ for each individual PFR Cheddar cheese formulation $(P>$ $0.05)$, indicating good reproducibility in the cheesemaking procedures over consecutive days.

\section{Descriptive Sensory Analysis}

Mixed model ANOVA indicated the trained panel differentiated the flavor (age, brothy, diacetyl, free fatty acid, fruity, milkfat, nutty, and sulfur) and taste (bitter, salty, sour, sweet, and umami) of Cheddar cheese over time, but not between PFR formulations. After repeated measures analysis, it was determined that PFR formulation had no effect $(P>0.05)$ on any of the flavor or taste intensities and no interaction $(P>0.05)$ was present between formulation and time for any attributes of flavor or taste. Although panelists were trained to minimize inherent variation in sensory perception (20 h of initial training and $6 \mathrm{~h}$ of additional calibration training), a panelist effect is likely responsible for some variation in the mean separation for Cheddar cheese over time as there is a strong tendency for measure- 
Table 3. Flavor sensory attributes of Cheddar cheese by aging time as evaluated by a trained panel $(\mathrm{n}=10)$ along a 15 -cm line scale

\begin{tabular}{lcccccccc}
\hline & \multicolumn{7}{c}{ Intensity } \\
\cline { 2 - 8 } Time (mo) & Age & Brothy & Diacetyl & FFA $^{1}$ & Fruity & Milk fat & Nutty & Sulfur \\
\hline 2 & $2.44^{\mathrm{d}}$ & $3.11^{\mathrm{c}}$ & $3.03^{\mathrm{b}}$ & $2.42^{\mathrm{ab}}$ & $2.00^{\mathrm{a}}$ & $5.03^{\mathrm{a}}$ & $2.26^{\mathrm{c}}$ & $1.61^{\mathrm{bc}}$ \\
5 & $4.13^{\mathrm{c}}$ & $4.33^{\mathrm{b}}$ & $2.90^{\mathrm{b}}$ & $2.31^{\mathrm{b}}$ & $2.39^{\mathrm{a}}$ & $3.76^{\mathrm{b}}$ & $3.06^{\mathrm{a}}$ & $1.55^{\mathrm{c}}$ \\
8 & $4.57^{\mathrm{bc}}$ & $4.40^{\mathrm{ab}}$ & $3.56^{\mathrm{a}}$ & $2.68^{\mathrm{ab}}$ & $2.04^{\mathrm{a}}$ & $4.04^{\mathrm{ab}}$ & $2.95^{\mathrm{ab}}$ & $1.89^{\mathrm{ab}}$ \\
10 & $4.98^{\mathrm{b}}$ & $4.20^{\mathrm{b}}$ & $3.40^{\mathrm{ab}}$ & $2.69^{\mathrm{ab}}$ & $2.06^{\mathrm{a}}$ & $4.16^{\mathrm{ab}}$ & $2.84^{\mathrm{ab}}$ & $2.08^{\mathrm{a}}$ \\
11 & $5.02^{\mathrm{ab}}$ & $4.54^{\mathrm{a}}$ & $3.20^{\mathrm{ab}}$ & $2.57^{\mathrm{ab}}$ & $2.05^{\mathrm{a}}$ & $4.47^{\mathrm{a}}$ & $2.73^{\mathrm{ab}}$ & $1.94^{\mathrm{a} c}$ \\
12 & $5.17^{\mathrm{a}}$ & $4.68^{\mathrm{a}}$ & $3.31^{\mathrm{ab}}$ & $2.71^{\mathrm{a}}$ & $2.08^{\mathrm{a}}$ & $4.30^{\mathrm{ab}}$ & $2.67^{\mathrm{b}}$ & $1.83^{\mathrm{abc}}$ \\
\hline
\end{tabular}

${ }^{a-d}$ Means within a column with different superscripts differ $(P<0.05)$.

${ }^{1} \mathrm{FFA}=$ free fatty acid.

ments made closer in time to be more highly associated than measurements made further apart (Moser, 2004).

Aging time influenced many flavor (Table 3) and taste (Table 4) intensities of Cheddar cheese when analyzed using mixed-model ANOVA with repeated measures with best fit covariance matrix. Age, brothy, milkfat, nutty, and sulfur flavors changed over the 12mo ripening period $(P<0.05)$ following both linear and quadratic trends. Positive linear and quadratic trends were present for age and brothy flavor $(P<0.05)$, with lowest perceptions seen at 2 mo, increasing up to the highest perceptions at 12 mo. Perception of nutty flavor was lowest at $2 \mathrm{mo}$, with linear and quadratic trends $(P$ $<0.05$ ), increasing nutty flavor from 5 to $11 \mathrm{mo}$, and decreasing slightly at 12 mo. A linear decrease in milkfat flavor was seen for Cheddar cheese aged from 2 to 5 mo of age $(P<0.05)$ and remained relatively constant through the rest of the ripening period. Sulfur flavor was variable $(P<0.05)$, starting with lower perceptions at 2 and $5 \mathrm{mo}$, increasing to $11 \mathrm{mo}$, and then decreasing again at $12 \mathrm{mo}$. Some variation in significance seen in the mean separation attributes was likely due to panelist effect over time. Generally, the mean values were close to one another (within $1 \mathrm{~cm}$ apart) and on the low end of the 15-cm scale. To support use of the higher end of the scale, the intensities of the reference

Table 4. Taste sensory attributes by aging time of Cheddar cheese as evaluated by a trained panel $(\mathrm{n}=10)$ along a 15 -cm line scale

\begin{tabular}{lccccc}
\hline & \multicolumn{5}{c}{ Intensity } \\
\cline { 2 - 6 } Time (mo) & Bitter & Salty & Sour & Sweet & Umami \\
\hline 2 & $2.23^{\mathrm{c}}$ & $3.46^{\mathrm{b}}$ & $2.35^{\mathrm{c}}$ & $2.95^{\mathrm{a}}$ & $4.11^{\mathrm{b}}$ \\
5 & $2.20^{\mathrm{c}}$ & $4.06^{\mathrm{a}}$ & $2.94^{\mathrm{b}}$ & $2.69^{\mathrm{ab}}$ & $4.60^{\mathrm{a}}$ \\
8 & $3.29^{\mathrm{a}}$ & $4.39^{\mathrm{a}}$ & $3.48^{\mathrm{a}}$ & $2.43^{\mathrm{bd}}$ & $4.42^{\mathrm{ab}}$ \\
10 & $3.02^{\mathrm{a}}$ & $4.14^{\mathrm{a}}$ & $2.66^{\mathrm{bc}}$ & $2.36^{\mathrm{bc}}$ & $4.58^{\mathrm{ab}}$ \\
11 & $2.78^{\mathrm{ab}}$ & $3.98^{\mathrm{a}}$ & $2.76^{\mathrm{bc}}$ & $2.17^{\mathrm{cd}}$ & $4.70^{\mathrm{a}}$ \\
12 & $2.61^{\mathrm{bc}}$ & $4.19^{\mathrm{a}}$ & $2.81^{\mathrm{bc}}$ & $2.55^{\mathrm{b}}$ & $4.85^{\mathrm{a}}$ \\
\hline
\end{tabular}

${ }^{\mathrm{a}-\mathrm{d}}$ Means within a column with different superscripts differ $(P<0.05)$. standards used during training should be decreased in future studies.

All 5 tastes (bitter, salty, sour, sweet, and umami) evaluated by trained panelists also changed over time $(P<0.05)$ characterized by linear, quadratic, and cubic trends. Bitterness followed linear and quadratic trends $(P<0.05)$, increasing up to 8 mo and slowly decreasing toward 12 mo. Linear and quadratic trends were also seen for saltiness $(P<0.05)$, in which perception was lowest at $2 \mathrm{mo}$, increased at $5 \mathrm{mo}$, and remained constant for the remainder of ripening. Quadratic and cubic trends were present for sourness $(P<0.05)$, as intensity was lowest at $2 \mathrm{mo}$, reaching its peak at $8 \mathrm{mo}$, and began to decrease toward 12 mo. Sweet perception showed a linear decrease from 2 to 11 mo $(P<0.05)$, with a slight increase seen at 12 mo. Umami taste was lowest at $2 \mathrm{mo}$, increased to $5 \mathrm{mo}$, and was relatively stable for the remainder of the ripening period $(P<$ $0.05)$.

Differences among Cheddar cheese PFR formulations and aging time for flavor and taste were visualized using PCA (Figure 1). The first 2 principal component (PC) factors explained $71 \%$ of the variability among the Cheddar cheese samples. The angle and length of each flavor or taste attribute vector, as well as its proximity to a given Cheddar cheese sample, indicate degree of association. Based on where each PFR formulation at each given aging time falls in this 2-dimensional plot, it is possible to explain how Cheddar cheese flavor and taste changed over time for each formulation. Principal component loading factors $>|0.500|$ indicate attributes of primary importance, as well as directionality. The first principal component, PC1, contributed $48 \%$ of the variability, primarily differentiating cheeses by flavors (age, brothy, diacetyl, free fatty acid, nutty, and sulfur) and tastes (bitter, salty, umami) loading positively, whereas milkfat flavor and sweet taste loaded negatively. A high intensity of milkfat was indicated for the 3 PFR formulations at 2 mo, whereas high intensities of flavors (age, brothy, diacetyl, free fatty acid, 
nutty, and sulfur) and tastes (bitter, salty, umami) were indicated for 3 PFR formulations at 8, 10, 11, and 12 mo. A high intensity of sweet taste was indicated for the 5-mo LPFR and MPFR. Results support previous research (Drake et al., 2001; Young et al., 2004; Iwasawa et al., 2014) in which young cheeses were more highly associated with underdeveloped flavor like sweet and milkfat, whereas aged cheeses showed higher intensities of age, brothy, nutty, salty, sour, sulfur, and umami. Furthermore, results agreed with the Washington State University Creamery's descriptions of their aged white Cheddar cheese characterized by brothy, nutty, and sulfur flavors (Steury 2013).

The second principal component, PC2 (24\%), differentiated cheeses by flavor (fruity, nutty) and sour taste loading positively, whereas flavors (diacetyl, milkfat, sulfur) and bitter taste loaded negatively. All 3 PFR formulations at 5 mo separated positively with PC2, indicating higher intensities of fruity, nutty, and sour attributes, while all formulations at the remaining time periods separated negatively. Overall, PCA separated the 2- and 5-mo cheeses into clear groupings with distinct young cheese characteristics, whereas cheeses at $8,10,11$, and 12 mo were clustered closer together, indicating that these cheeses were more similar in flavor and taste.

\section{Electronic Tongue Analysis}

Principal component analysis was used to look at each PFR formulation individually over the 12-mo aging period. The discrimination index shown on each PCA graph indicates the extent of similarity and difference among samples. With each triangular plot on the graph representing a sample, nonoverlapping triangles show complete discrimination or distinct differences among samples according to their electronic tongue outputs and vice versa. A high discrimination index (a maximum of 100) shows large differences among samples, whereas a poor discrimination index (minimum of $-100)$ shows strong similarity among samples.

Electronic tongue output for the LPFR formulation at all aging time points shows a moderate discrimination index of 56 (Figure 2). The first $2 \mathrm{PC}$ explained $77 \%$ of the variability between the aging time periods for the LPFR. The PC1 explained $46 \%$ of the variation between aging time points, with the bitter, spicy, sour, salty, and sweet sensors (loading negatively) characterizing the 8-, 11-, and 12-mo LPFR, whereas the metallic and umami sensors (loading positively) characterized the 2-, 5-, and 10-mo LPFR. Twelve months was most highly correlated with the bitter, sweet, spicy, and salty sensors, whereas the sour sensor was more associated with 8- and 11-mo LPFR. At 2 and 5 mo, the LPFR was more associated with the metallic sensor, whereas the 10-mo LPFR was associated with the umami sensor. The PC2 explained $31 \%$ of the variability between the time periods, separating 5 and 12 mo from 8 and 10 mo. At 2 and 11 mo, triangles crossed the plane of $\mathrm{PC} 2$, indicating similarity in taste intensities to all 4 of the other formulations on PC2.

Electronic tongue output for the MFPR formulation at all aging time points had a lower discrimination index of 38 when analyzed using PCA (Figure 3). The first $2 \mathrm{PC}$ explained $62 \%$ of the variability between the aging time periods for the MPFR. The PC1 explained $36 \%$ of the variation between time points, with the bitter, spicy, sour, salty, and sweet sensors (loading negatively) characterizing 8- and 12-mo MPFR, whereas the metallic and umami sensors (loading positively) associated with 2-, 5-, 10-, and 11-mo MPFR. At 2 and 5 mo, the MPFR formulations were more associated with the metallic and umami sensors than the 10- and 11mo cheeses. The PC2 explained $26 \%$ of the variability between the time periods of the MPFR, separating the 10-mo MPFR from 2- and 5-mo MPFR. The MPFR at 8,11 , and 12 mo crossed between planes of PC2.

Electronic tongue output for the HPFR formulation at all aging time points was analyzed using PCA with the highest discrimination index of 66 (Figure 4). The first $2 \mathrm{PC}$ explained $82 \%$ of the variability between the aging time periods of the HPFR. The PC1 explained $60 \%$ of the variation between time points, with the bitter and umami sensors (loading negatively) associating with 2- and 5-mo HPFR very slightly, whereas the salty, spicy, sour, and sweet sensors (loading positively) characterized 8-, 10-, 11-, and 12-mo HPFR. The 8-mo HPFR was most associated with the salty and spicy sensors, whereas the sour sensor was most associated with 11- and 12-mo HPFR. The 10-mo HPFR was most associated with the sweet sensor. The PC2 explained $21 \%$ of the variability between the time periods, separating 8 mo from 2-, 10-, and 11-mo HPFR. At 2, 10, and $11 \mathrm{mo}$, the HPFR was associated with the metallic sensor (loading negatively). At 5 and 12 mo, the HPFR crossed between planes of $\mathrm{PC} 2$.

In general, the sensor profiles were very similar for the LPFR and MFPR formulations over time. At 2 mo, the LPFR and MPFR shared the highest intensities for all 7 sensors; LPFR was more bitter, salty, spicy, and sour, whereas the MFPR was more metallic, sweet, and umami. This changed slightly as the formulations aged to 5 and $8 \mathrm{mo}$, with the LPFR continuing to have the highest intensities for all except the umami sensor, which now exhibited its highest intensity for the MPFR. The 2-, 5-, and 10-mo LPFR were most highly associated with the metallic and umami sensors, which was mirrored by the $2,5,10$, and 11 mo of the 
MPFR formulation. The 8, 10, and 12 mo of the LPFR formulation had the highest intensities of bitter, salty, spicy, sour, and sweet, mirrored by the 8 and 12 mo of the MPFR. The similarity between LPFR and MPFR could be due to the smaller difference in their PFR (0.11) compared with their difference from the HPFR.

The HPFR followed a distinctive pattern for sensor intensities over aging time. The HPFR had the lowest

Biplot (axes PC1 and PC2: $71.3 \%$ )

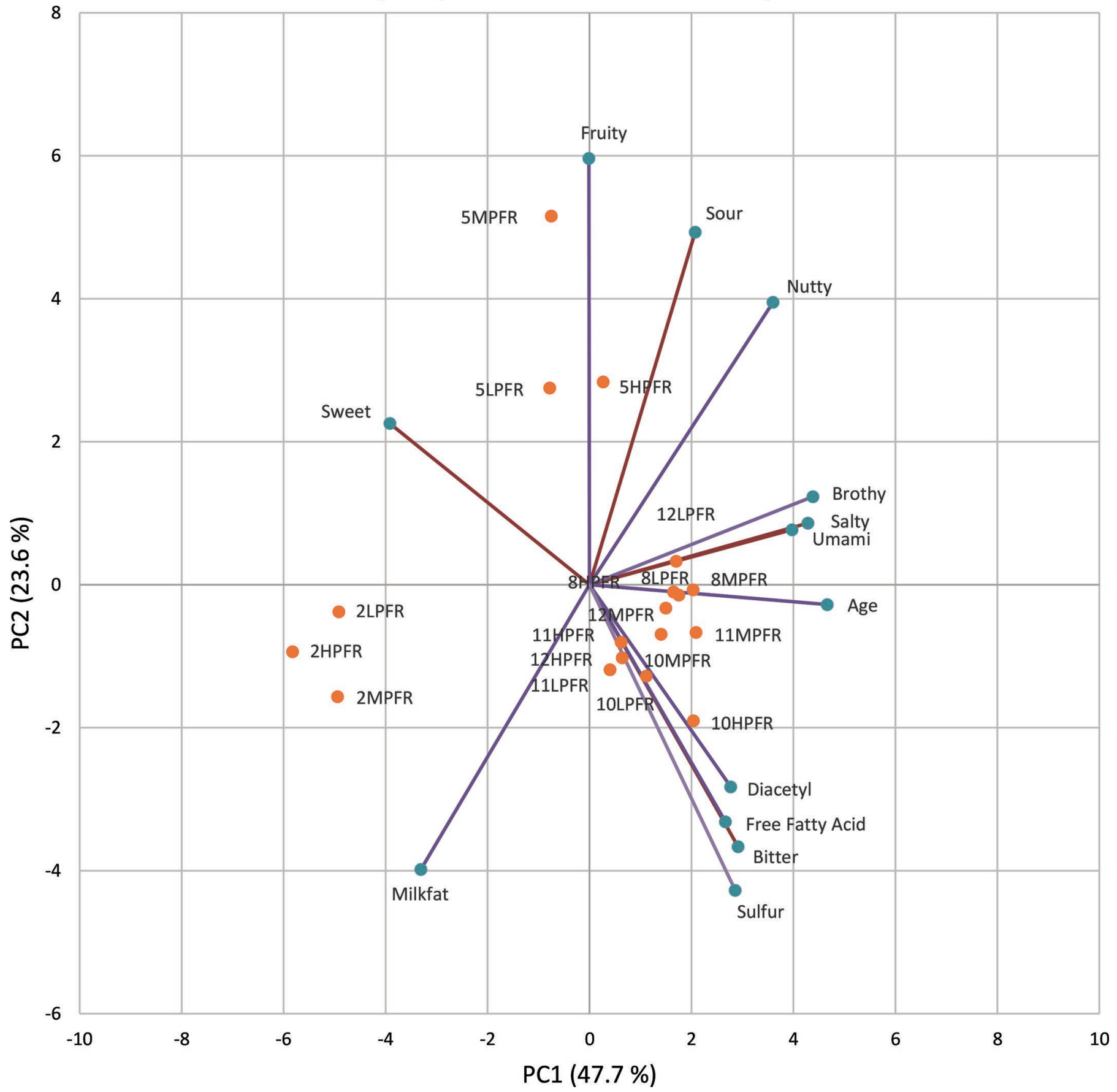

Figure 1. Principal component (PC) analysis biplot of flavor (purple vectors) and taste (orange vectors) sensory attributes for protein-to-fat ratio $(\mathrm{PFR})$ Cheddar cheese formulations evaluated by a trained panel $(\mathrm{n}=10)$ over 12 mo. Cheeses are indicated by aging time $(2,5,8,10$, 11 , or $12 \mathrm{mo}$ ) and formulation: LPFR = low PFR; MPFR = medium PFR; HPFR = high PFR 


\section{Discrimination index $=56$}

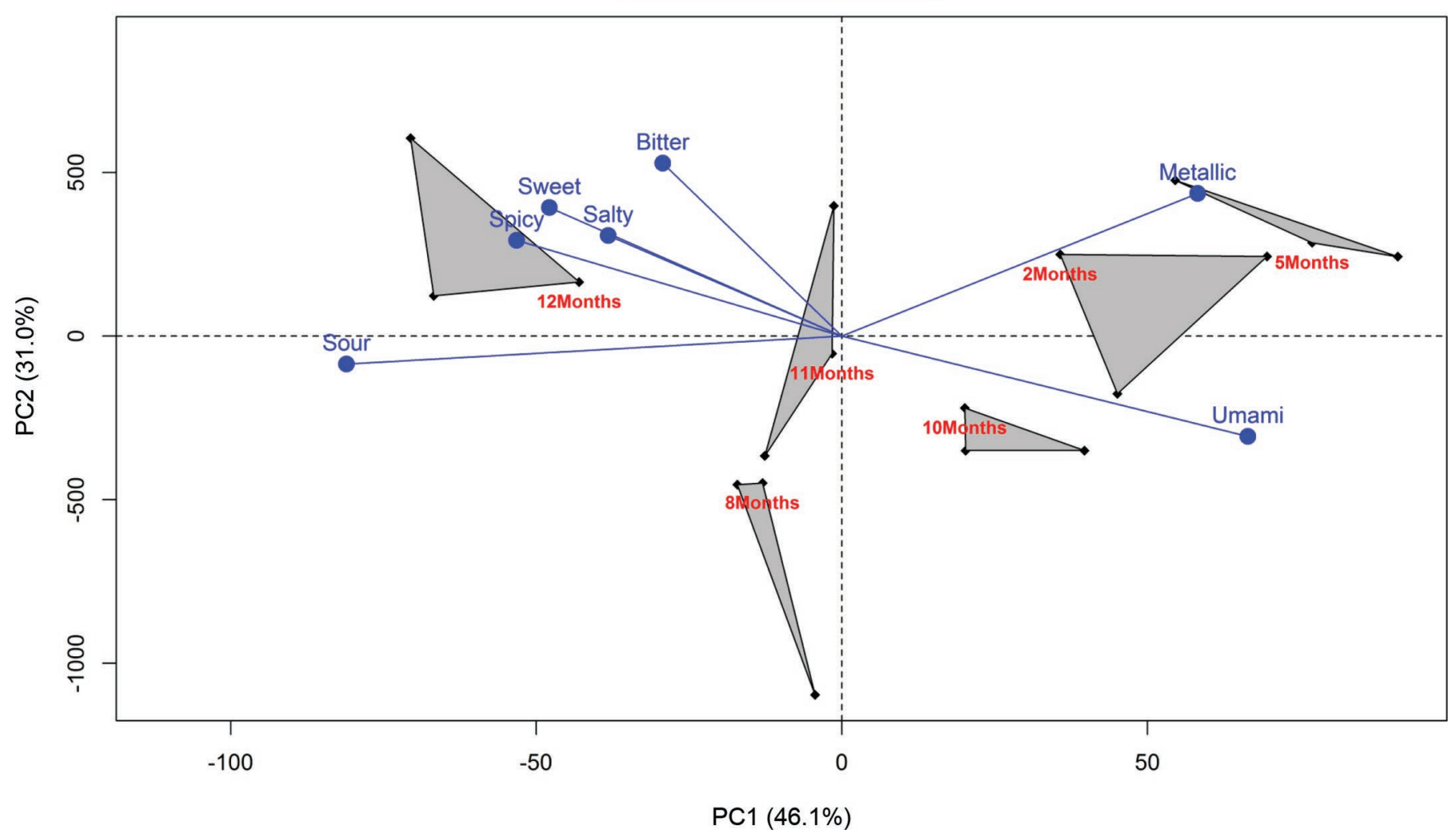

Figure 2. Electronic tongue discrimination of low protein-to-fat ratio (0.74) Cheddar cheese over 12 mo of aging with moderate discrimination index (56) based on Astree set \#5 sensors (Alpha MOS, Toulouse, France). The sensors are indicated by bitter, metallic, spicy, sour, salty, sweet, and umami. Each data point in a triangle represents a batch. $\mathrm{PC}=$ principal component. Color version available online.

intensities detected for all 7 sensors at 2, 5, and 8 mo. At 2 and 5 mo, the HPFR was associated most highly with the bitter sensor. At 10 and 11 mo, the HPFR had a high intensity for both the bitter and metallic sensor. At $8,10,11$, and $12 \mathrm{mo}$, the HPFR was associated with high intensities from the salty, spicy, sour, and sweet sensors. The HPFR began to associate more highly with sensors at $10 \mathrm{mo}$, increasing intensities of sweet and sour, whereas the LPFR remained associated with the bitter, spicy, and salty sensors, and the MPFR with the metallic and umami sensors. At 11 mo, the HPFR was characterized with higher intensities from the spicy and umami sensors. By 12 mo, the LPFR exhibited the highest intensities for the bitter, sweet, and umami sensors; the MPFR for the sour sensor; and the HPFR for the metallic, spicy, and salty sensor.

Discriminant analysis showed a $100 \%$ classification for the training samples (Table 5). This is the most optimistic model as the same samples used in building the model were classified. However, cross-validated results using the leave-one-out method showed a percent correct range from 33 to 100 . The similarity among the electronic tongue profiles of LPFR and MPFR is also observed in the low percent correct cross-validation results from discriminant analysis. These PFR formulations had similar trends in signal intensity profiles across the aging time and hence, the poor classification rates. The distinctive pattern of signal profiles observed in HPFR resulted in $100 \%$ cross-validation. This implies that the HPFR was distinctly different in its electronic tongue profile compared with the other 2 PFR formulations. Similarly, cheeses aged 2, 8, and 12 mo were distinctly different from the 5-, 10-, and 11-mo cheeses as seen from high training and cross-validated percent correct classification rates.

Electronic tongue analysis allowed for profiling of Cheddar cheese based on PFR formulation and aging time for bitter, metallic, salty, sour, spicy, sweet, and umami taste intensities. Partial least squares analysis between electronic tongue output and descriptive sensory analysis indicated moderate to high coefficients of determination ( $\mathrm{R}^{2}$ above 0.50$)$ for all Cheddar cheese flavor and taste attributes during aging (Tables 6 and 7). The lowest correlation coefficients between the elec- 
tronic tongue and descriptive sensory analysis outputs were observed in the MPFR formulation and may be due to the linking of twice as many electronic tongue runs through reference compensation than the LPFR and HPFR formulations, leading to more variation between sensor outputs.

Extraction was performed in this study to avoid a residual fat film from accumulating on the sensors during analysis. The fat film can interfere with the functioning of the sensors and may lead to unresponsive sensors. Due to the extraction process, some neutral and basic free fatty acids and their derivatives (alcohols, aldehydes, esters, ketones, and sulfur compounds), as well as bitter hydrophobic peptides, may have been removed from the cheese extract (Collins et al., 2003; Carunchia Whetstine et al., 2006). However, at the $\mathrm{pH}$ of Cheddar cheese $(\sim 5.2)$, a considerable portion of free fatty acids and their constituents are present as nonvolatile salts (Singh et al., 2003) and the chloroform:methanol extraction removed only 2 to $5 \%$ of salts from Cheddar cheese (data not shown). Flavors and tastes that may have been affected by fat removal include age, fruity, sulfur, brothy, nutty, and bitter (Carunchia Whetstine et al., 2006); however, all correlations between the electronic tongue and sensory analysis remained above 0.50 .

\section{Consumer Sensory Evaluation}

Consumers evaluated the Cheddar cheeses for acceptability ratings and intensity of flavors and tastes at 12 mo of aging. Consumer panel results indicated that liking ratings (aged/sharp flavor, Cheddar cheese flavor, firmness, milky/dairy flavor, overall flavor, overall liking, overall texture, and salty taste), intensity ratings (aged/sharp flavor, Cheddar cheese flavor, milky/ dairy flavor, and salty taste) and purchase intent varied with PFR formulation $(P<0.05)$. Aroma was the same $(P>0.05)$ among the PFR cheese formulations.

Liking ratings were about 6 to 7 , corresponding to "like slightly" and "like moderately" (Table 8). All intensity ratings were above 4.5 , indicating moderate intensity of the attributes. The LPFR and MPFR had higher ratings for overall flavor than the $\operatorname{HPFR}(P<$

\section{Discrimination index $=38$}

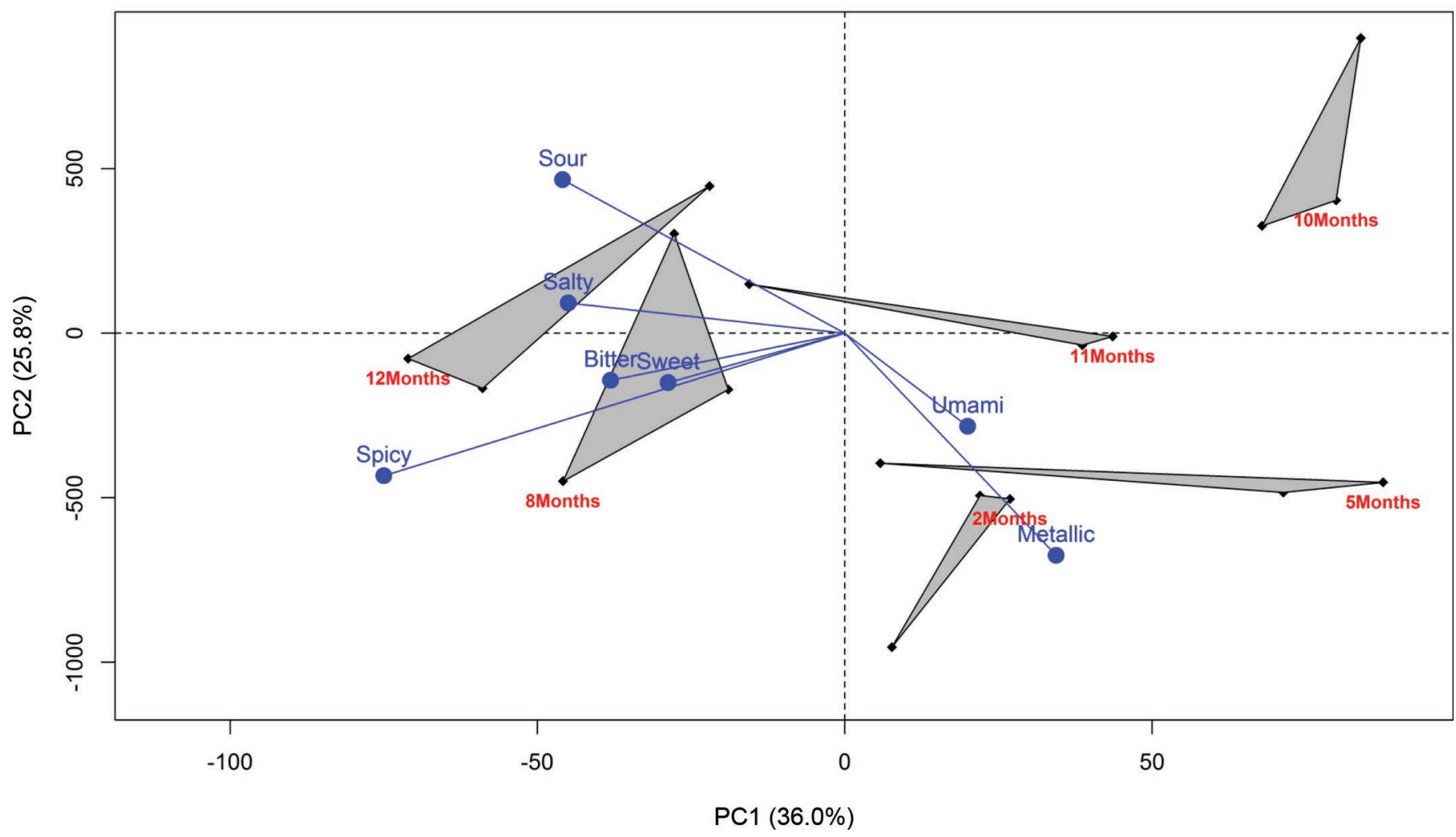

Figure 3. Electronic tongue discrimination of medium protein-to-fat ratio (0.85) Cheddar cheese over 12 mo of aging with moderate discrimination index (38) based on Astree set \#5 sensors (Alpha MOS, Toulouse, France). The sensors are indicated by bitter, metallic, spicy, sour, salty, sweet, and umami. Each data point in triangle represents a batch. $\mathrm{PC}=$ principal component. Color version available online. 


\section{Discrimination index $=67$}

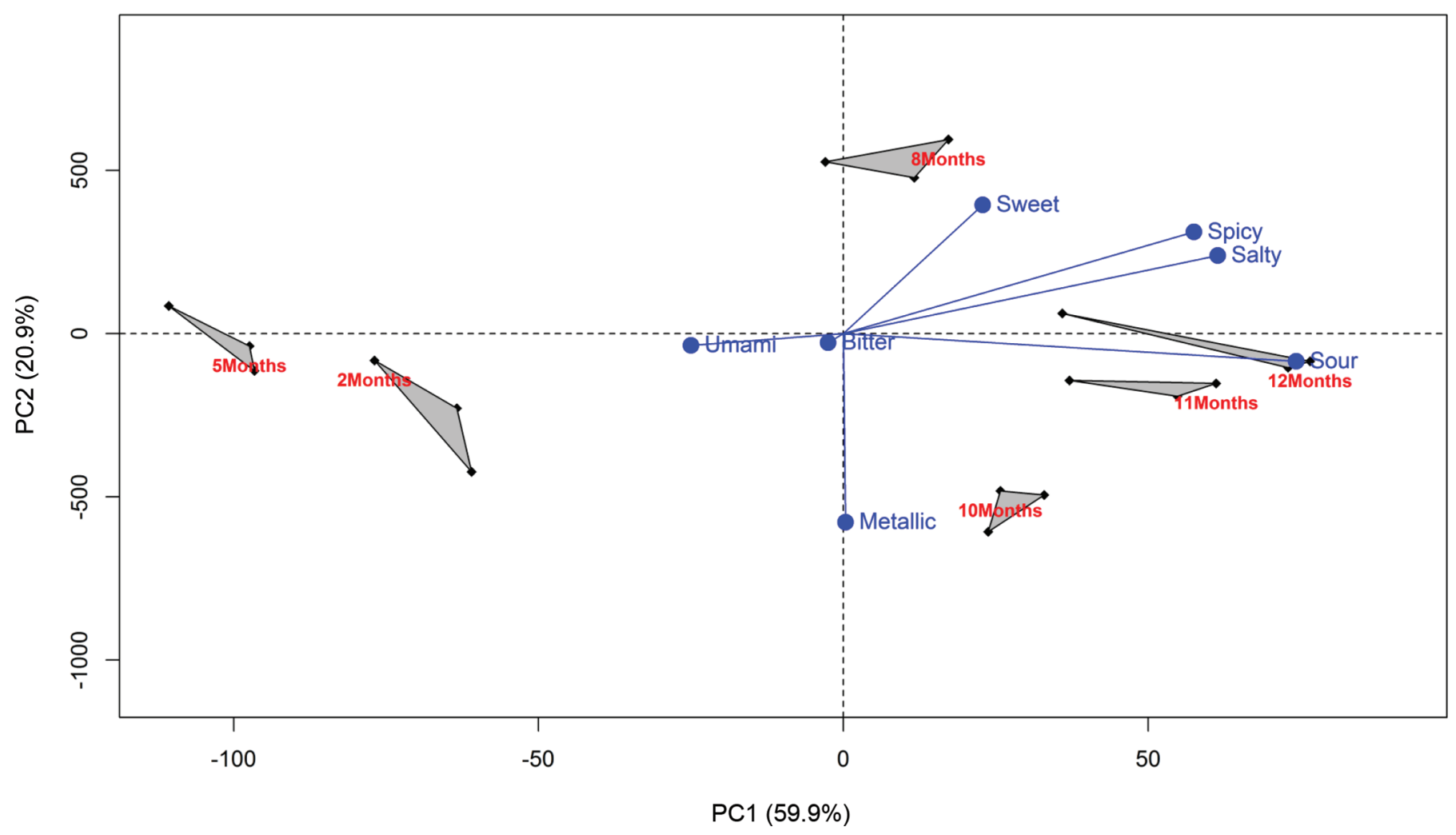

Figure 4. Electronic tongue discrimination of high protein-to-fat ratio (1.01) Cheddar cheese over 12 mo of aging with moderate discrimination index (66) based on Astree set \#5 sensors (Alpha MOS, Toulouse, France). The sensors are indicated by bitter, metallic, spicy, sour, salty, sweet, and umami. Each data point in a triangle represents a batch. $\mathrm{PC}=$ principal component. Color version available online.

0.05). This was mirrored in liking ratings for aged/ sharp flavor, Cheddar cheese flavor, milky/dairy flavor, and salty taste as well as intensity ratings for these attributes, indicating that higher intensities of these flavors were associated with higher liking ratings for the specific flavor and for overall flavor of cheese. The LPFR and MPFR were also characterized by higher ratings for overall liking than the HPFR $(P<0.05)$, indicating that the perception of flavor has a large influence on overall acceptability of consumers. A higher rating for purchase intent for the LFPR and MPFR indicated "would purchase," rather than "may or may not purchase" for the HPFR. The MPFR was associated with the highest liking ratings for firmness and overall

Table 5. Percent correct classification of protein-to-fat ratio (PFR) Cheddar cheese formulations aged between 2 and 12 mo

\begin{tabular}{lccc}
\hline Sample & No. of samples & $\begin{array}{c}\text { \% Correct for } \\
\text { training sample }\end{array}$ & $\begin{array}{c}\text { \% Correct for } \\
\text { cross-validation }\end{array}$ \\
\hline $\begin{array}{l}\text { PFR } \\
\text { Low }\end{array}$ & 6 & 100 & 33 \\
Medium & 6 & 100 & 33 \\
High & 6 & 100 & 100 \\
Aging (mo) & 3 & 100 & 100 \\
2 & 3 & 100 & 67 \\
5 & 3 & 100 & 67 \\
8 & 3 & 100 & 33 \\
10 & 3 & 100 & 100 \\
11 & 3 & 100 & \\
12 & 3 & & \\
\hline
\end{tabular}

${ }^{1}$ Validation $=$ leave-one-out cross-validation. 
Table 6. Partial least squares correlation between electronic tongue analysis and trained panel sensory evaluation for taste and flavor attributes of Cheddar cheese formulations at each aging time period

\begin{tabular}{|c|c|c|c|c|c|c|}
\hline \multirow[b]{2}{*}{ Attribute } & \multicolumn{6}{|c|}{ Coefficient of determination $\left(\mathrm{R}^{2}\right)$} \\
\hline & $2 \mathrm{mo}$ & $5 \mathrm{mo}$ & $8 \mathrm{mo}$ & $10 \mathrm{mo}$ & $11 \mathrm{mo}$ & $12 \mathrm{mo}$ \\
\hline \multicolumn{7}{|l|}{ Taste } \\
\hline Bitter & $0.984^{*}$ & $0.973^{*}$ & 0.724 & $0.893^{*}$ & $0.898^{*}$ & $0.885^{*}$ \\
\hline Salty & $0.971^{*}$ & $0.944^{*}$ & 0.732 & $0.850^{*}$ & 0.769 & 0.744 \\
\hline Sour & $0.912^{*}$ & $0.965^{*}$ & $0.820^{*}$ & 0.766 & $0.909^{*}$ & $0.870^{*}$ \\
\hline Sweet & $0.892^{*}$ & $0.947^{*}$ & $0.777^{*}$ & 0.500 & $0.871^{*}$ & $0.934^{*}$ \\
\hline Umami & $0.992^{*}$ & $0.947^{*}$ & $0.805^{*}$ & 0.505 & 0.671 & $0.932^{*}$ \\
\hline \multicolumn{7}{|l|}{ Flavor } \\
\hline Age & 0.745 & $0.994 *$ & $0.926^{*}$ & 0.787 & 0.659 & $0.870^{*}$ \\
\hline Brothy & $0.913^{*}$ & $0.980^{*}$ & $0.900^{*}$ & $0.827^{*}$ & $0.905^{*}$ & $0.929^{*}$ \\
\hline Diacetyl & $0.821^{*}$ & $0.950^{*}$ & $0.894^{*}$ & 0.621 & $0.999^{*}$ & $0.988^{*}$ \\
\hline Fruity & $0.823^{*}$ & $0.956^{*}$ & 0.628 & 0.547 & 0.650 & $0.910^{*}$ \\
\hline $\mathrm{FFA}^{1}$ & $0.885^{*}$ & $0.969^{*}$ & $0.923^{*}$ & 0.605 & $0.851^{*}$ & $0.940^{*}$ \\
\hline Milk fat & $0.984^{*}$ & $0.958^{*}$ & 0.632 & 0.669 & 0.780 & $0.996^{*}$ \\
\hline Nutty & $0.985^{*}$ & $0.987^{*}$ & 0.633 & 0.504 & 0.637 & $0.916^{*}$ \\
\hline Sulfur & $0.961^{*}$ & $0.985^{*}$ & $0.927^{*}$ & $0.997^{*}$ & $0.831^{*}$ & $0.920^{*}$ \\
\hline
\end{tabular}

${ }^{1} \mathrm{FFA}=$ free fatty acid.

*Strong correlation defined as $\mathrm{R}^{2}>0.80$.

texture $(P<0.05)$. Previous research has documented that consumers are less accepting of lower fat Cheddar cheeses (Childs and Drake, 2009). Overall, higher fat content was associated with increased flavor intensities in Cheddar cheese and drove consumer acceptability and purchase intent ratings.

Agglomerative hierarchical clustering revealed 3 clusters of consumers with different cheese preferences (Table 9). The majority of consumers were in cluster 3 (55 consumers), followed by cluster 2 (37 consumers), and cluster 1 with the fewest (28 consumers). Cluster 1 highly preferred the LPFR with a rating of approxi-

Table 7. Partial least squares correlation between electronic tongue analysis and trained panel sensory evaluation for taste and flavor attributes over 12 mo of aging for individual low, medium, and high protein-to-fat ratio (LPFR, MPFR, and HPFR, respectively) Cheddar cheese formulations

\begin{tabular}{llll}
\hline & \multicolumn{3}{c}{ Coefficient of determination $\left(\mathrm{R}^{2}\right)$} \\
\cline { 2 - 4 } Attribute & LPFR & MPFR & HPFR \\
\hline Taste & & & \\
Bitter & $0.990^{*}$ & 0.762 & $0.998^{*}$ \\
Salty & $0.997^{*}$ & $0.968^{*}$ & $0.985^{*}$ \\
Sour & $0.988^{*}$ & 0.642 & $0.996^{*}$ \\
Sweet & $0.993^{*}$ & $0.804^{*}$ & $0.988^{*}$ \\
Umami & $0.998^{*}$ & 0.640 & $0.988^{*}$ \\
Flavor & & & \\
Age & $0.977^{*}$ & $0.948^{*}$ & $0.992^{*}$ \\
Brothy & $0.990^{*}$ & $0.995^{*}$ & $0.990^{*}$ \\
Diacetyl & $0.981^{*}$ & 0.778 & $0.999^{*}$ \\
Fruity & $0.991^{*}$ & $0.926^{*}$ & $0.993^{*}$ \\
Free fatty acid & $0.992^{*}$ & $0.995^{*}$ & $0.984^{*}$ \\
Milk fat & $0.983^{*}$ & $0.893^{*}$ & $0.992^{*}$ \\
Nutty & $0.983^{*}$ & $0.853^{*}$ & $0.994^{*}$ \\
Sulfur & $0.999^{*}$ & $0.864^{*}$ & $0.977^{*}$ \\
\hline
\end{tabular}

*Strong correlation defined as $\mathrm{R}^{2}>0.80$. mately 7.9, indicating "like very much," in comparison to the MPFR and HPFR formulations with ratings of 6.4 and 5.3, respectively, indicating "like moderately" and "like slightly." Cluster 2 preferred the HPFR (7.5), followed by the LPFR (6.8), and least preferred the MPFR (5.7). Cluster 3 preferred the MPFR (7.5) over both the LPFR (6.5) and HPFR (5.6). After analyzing consumer demographic information, age served as

Table 8. Mean intensities for liking and intensity parameters of protein-to-fat ratio (PFR) Cheddar cheese formulations aged for 12 mo and evaluated by a consumer panel $(n=120)$

\begin{tabular}{llll}
\hline & \multicolumn{3}{c}{ PFR } \\
\cline { 2 - 4 } Item & Low & Medium & High \\
\hline Liking attribute $^{1}$ & & & \\
Aged or sharp flavor & $6.78^{\mathrm{a}}$ & $6.83^{\mathrm{a}}$ & $6.12^{\mathrm{b}}$ \\
Appearance & $7.17^{\mathrm{a}}$ & $7.34^{\mathrm{a}}$ & $7.22^{\mathrm{a}}$ \\
Aroma & $7.07^{\mathrm{a}}$ & $7.20^{\mathrm{a}}$ & $6.90^{\mathrm{a}}$ \\
Cheddar cheese flavor & $7.06^{\mathrm{a}}$ & $6.95^{\mathrm{a}}$ & $6.59^{\mathrm{b}}$ \\
Crumbliness & $6.29^{\mathrm{a}}$ & $6.40^{\mathrm{a}}$ & $6.36^{\mathrm{a}}$ \\
Firmness & $6.49^{\mathrm{b}}$ & $7.03^{\mathrm{a}}$ & $6.75^{\mathrm{ab}}$ \\
Milky or dairy flavor & $6.59^{\mathrm{a}}$ & $6.47^{\mathrm{a}}$ & $6.07^{\mathrm{b}}$ \\
Overall flavor & $7.18^{\mathrm{a}}$ & $7.07^{\mathrm{a}}$ & $6.55^{\mathrm{b}}$ \\
Overall liking & $6.93^{\mathrm{a}}$ & $6.68^{\mathrm{a}}$ & $6.11^{\mathrm{b}}$ \\
Overall texture & $6.69^{\mathrm{ab}}$ & $6.98^{\mathrm{a}}$ & $6.53^{\mathrm{b}}$ \\
Salty taste & $6.49^{\mathrm{a}}$ & $6.33^{\mathrm{a}}$ & $5.97^{\mathrm{b}}$ \\
Intensity rating & & & \\
Aged or sharp flavor & $6.44^{\mathrm{a}}$ & $6.41^{\mathrm{a}}$ & $5.78^{\mathrm{b}}$ \\
Cheddar cheese flavor & $6.52^{\mathrm{a}}$ & $6.57^{\mathrm{a}}$ & $5.86^{\mathrm{b}}$ \\
Milky or dairy flavor & $5.73^{\mathrm{a}}$ & $5.36^{\mathrm{ab}}$ & $5.07^{\mathrm{b}}$ \\
Salty taste & $5.43^{\mathrm{a}}$ & $5.25^{\mathrm{a}}$ & $4.48^{\mathrm{b}}$ \\
Purchase intent & $3.61^{\mathrm{a}}$ & $3.51^{\mathrm{a}}$ & $3.06^{\mathrm{b}}$ \\
\hline
\end{tabular}

${ }^{\mathrm{a}, \mathrm{b}}$ Means within a row with different superscripts differ $(P<0.05)$.

${ }^{1}$ A 9 -point hedonic scale was used for liking and a 9-point intensity scale for intensity ratings.

${ }^{2} \mathrm{~A}$ hedonic 5-point scale was used for purchase intent. 
Table 9. Mean separation for liking ratings and purchase intent based on overall liking by cluster and protein-to-fat ratio (PFR) formulation ${ }^{1}$

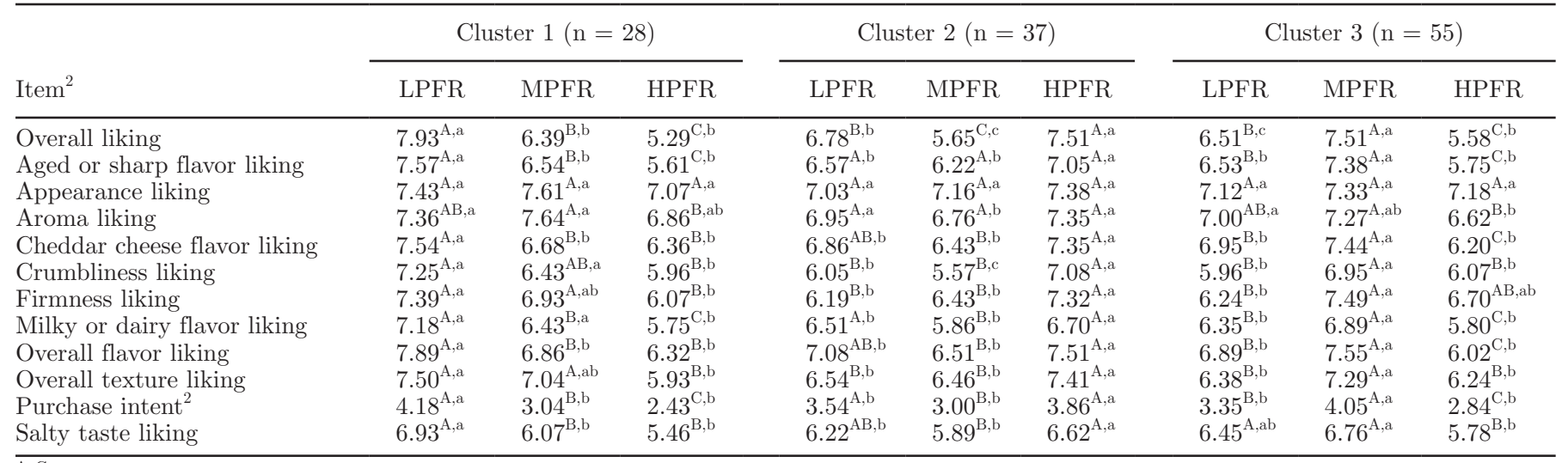

$\overline{\mathrm{A}-\mathrm{C}}$ Means within a cluster with different uppercase letters are statistically different $(P<0.05)$.

${ }^{\mathrm{a}-\mathrm{c}}$ Means across each PFR formulation with different lowercase letters are statistically different $(P<0.05)$.

${ }^{1} \mathrm{LPFR}=$ low PFR; MPFR $=$ medium PFR; HPFR $=$ high PFR.

${ }^{2}$ All liking ratings from a 9-point scale. Purchase intent from a 5-point scale.

a significant segmenting factor, with cluster 2 having a higher mean age of $41 \mathrm{yr}$, in comparison to cluster 1 (mean age 32 ) and cluster 2 (mean age 34 yr; $P<$ $0.05)$; thus, an increase in age was associated with a higher overall liking rating of the HPFR.

Partial least squares regression was conducted to determine the drivers of liking for each PFR Cheddar cheese samples using the trained panel data as dependent variables and the consumer sensory data as explanatory variables. Because there are 3 samples, the predictive model for only 2 dimensions ( $\mathrm{t} 1$ and $\mathrm{t} 2$ ) was presented in the circle of correlations (Figure 5). High correlation among many of the attributes resulted in overlapping points on the correlation plot; hence, not as many points can be seen on the plot as there are attributes. Also, all attributes were plotted on the circle of correlation because they were all well represented by the 2 dimensions.

The first component, t1, primarily served to separate the LPFR and MPFR (loading positively) from the HPFR (loading negatively). Intensities of flavors (fruity, brothy, milkfat, diacetyl, nutty, age) and tastes (sweet, salty, sour), liking scores (aroma, overall flavor, overall liking, overall texture, aged/sharp flavor, Cheddar cheese flavor, milky/dairy flavor, salty taste), intensity ratings (aged/sharp flavor, Cheddar cheese flavor, milky/dairy flavor, salty taste) and purchase intent were highly correlated with the LPFR and, subsequently, cluster 1 as shown previously in Table 9 . Overall liking was most highly correlated with overall flavor, purchase intent, Cheddar cheese flavor, milky/ dairy flavor, and salty taste liking $\left(\mathrm{R}^{2}>0.99\right)$. Each of the flavor liking and flavor intensity score pairings was highly correlated $\left(\mathrm{R}^{2}>0.93\right)$. A high intensity of sulfur flavor was associated with the HPFR and, subsequently, drove liking by cluster 2 as seen previously in Table 9. The second component, t2, of the correlation plot served primarily to separate the LPFR (loading positively) from the MPFR (loading negatively). Nutty and free fatty acid flavors associated with the LPFR, whereas bitter and umami tastes associated with the MPFR. Liking scores for aroma, appearance, crumbliness, firmness, and overall texture were more highly associated with the MPFR. Overall, flavor and taste of the LPFR drove higher overall liking by consumers, but the MPFR was seemingly optimized for texture.

\section{CONCLUSIONS}

Correlations between sensory and instrumental analyses suggest that the electronic tongue may have application for routine monitoring of Cheddar cheese formulations for flavor and taste. The electronic tongue may be more objective, rapid, cost effective, and sensitive than the use of human panelists. The electronic tongue detected smaller changes in tastes (bitter, metallic, salty, sour, spicy, sweet, and umami) of the 3 PFR formulations over time when compared with the trained panelists, who detected no differences, suggesting that the electronic tongue may be more sensitive to tastants than humans and may have the capability for early detection/identification of problems in a batch of cheese during aging. To enhance applicability by industry, an extensive library should be built with existing cheese to calibrate the sensors and learn the characteristics of an ideal product, so that the electronic tongue could be used to categorize cheese and ensure it meets manufacturer's specifications. Further 


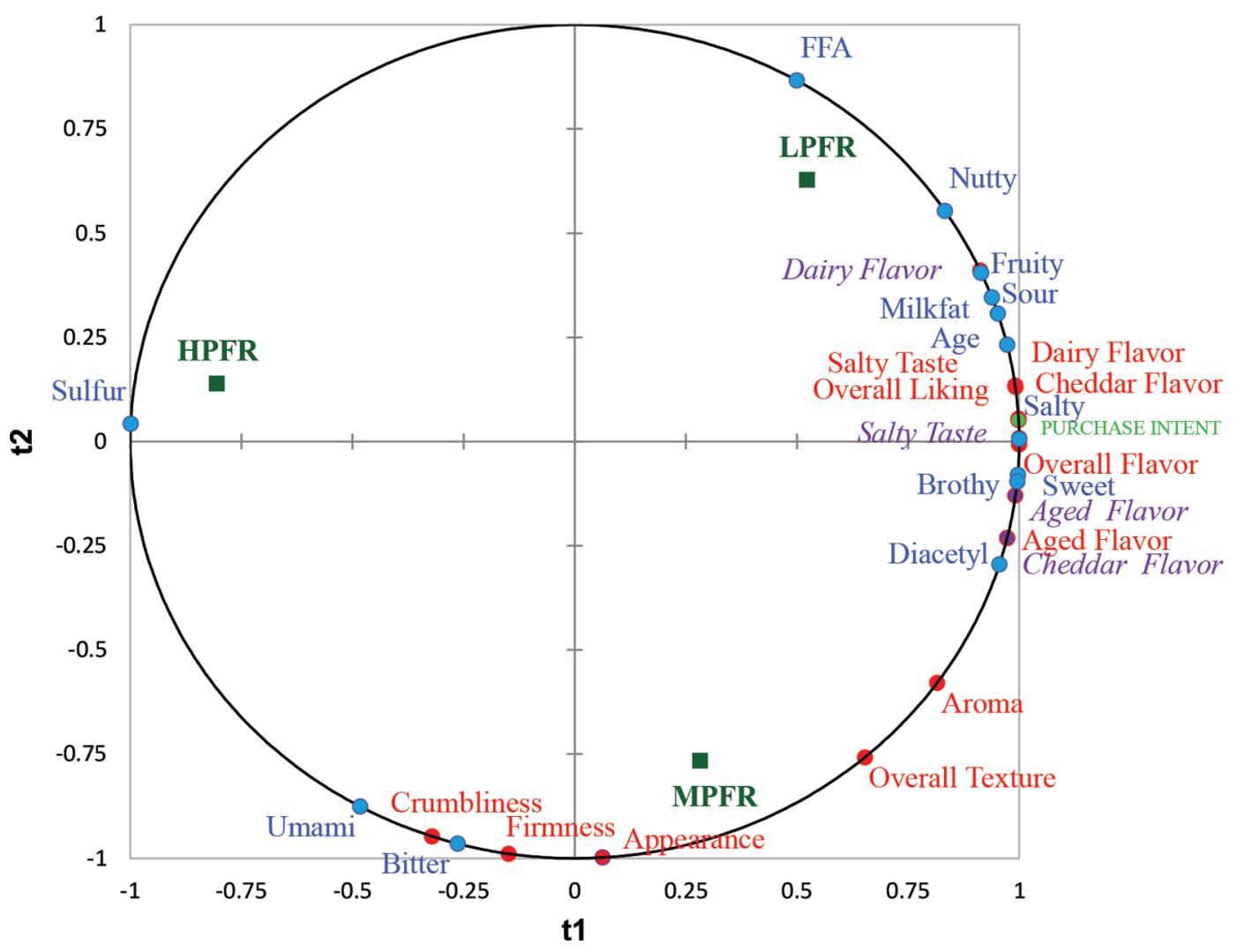

Figure 5. Partial least squares regression (PLSR) biplot correlating flavor attributes (blue labels) evaluated by the trained panel $(\mathrm{n}=10)$ to consumer liking ratings (red labels), intensity ratings (italicized purple labels), and purchase intent (uppercase green label; $\mathrm{n}=120$ ) for 12-moaged Cheddar cheese samples varying in protein-to-fat ratio (PFR). t1 = first component; $\mathrm{t} 2=$ second component; LPFR $=$ low PFR; MPFR $=$ medium PFR; HPFR = high PFR; FFA = free fatty acid.

analysis should be performed to see which electronic tongue sensors were associated with which taste and flavor attributes analyzed using descriptive sensory analysis. Finally, the extraction of lipids from cheese to prevent damage to the potentiometric sensors of the electronic tongue is a limitation to this study's methodology. Other fat extraction techniques, such as the use of petroleum ether, should be examined to minimize the loss of hydrophobic peptides, free fatty acids, and their derivatives. Further studies could also explore coupling the electronic nose with the electronic tongue results to minimize this limitation.

\section{ACKNOWLEDGMENTS}

The authors thank Beata Vixie (School of Food Science, Washington State University, Pullman) for her advice and support with the sensory panels and staff of the Washington State University Creamery (Pullman) for partial funding and technical assistance with cheese production.

\section{REFERENCES}

AOAC International. 2000. Official Methods of Analysis. 17th ed. AOAC International, Gaithersburg, MD.

Banks, J. M. 2004. The technology of low-fat cheese manufacture. Int. J. Dairy Technol. 7:199-207.

Carunchia Whetstine, M. E., M. A. Drake, B. K. Nelson, and D. M. Barbano. 2006. Flavor profiles of full-fat and reduced-fat cheese and cheese fat made from aged Cheddar with the fat removed using a novel process. J. Dairy Sci. 89:505-517.

Childs, J. L., and M. Drake. 2009. Consumer perception of fat reduction in cheese. J. Sens. Stud. 24:902-921.

Clark, S., M. Costello, M. Drake, and F. Bodyfelt. 2009. The sensory evaluation of dairy products. Pages 1-573. Vol. 2. Springer-Verlag, New York, NY.

Code of Federal Regulations. 2016. Title 21-Food and drugs. Part 133. Cheese and cheese products. US Government Printing Office, Washington, DC.

Collins, Y. F., P. L. H. McSweeney, and M. G. Wilkinson. 2003. Lipolysis and free fatty acid catabolism in cheese: A review of current knowledge. Int. Dairy J. 13:841-866.

Drake, M. A., S. C. McIngvale, P. D. Gerard, K. R. Cadwallader, and G. V. Civille. 2001. Development of a descriptive language for Cheddar cheese. J. Food Sci. 66:1422-1427.

Drake, S. L., M. E. Carunchia Whetstine, M. A. Drake, P. Courtney, K. Fligner, J. Jenkins, and C. Pruitt. 2007. Sources of umami taste in Cheddar and Swiss cheese. J. Food Sci. 72:S360-S366.

Drake, S. L., K. Lopetcharat, S. Clark, H. S. Kwak, S. Y. Lee, and M. A. Drake. 2009. Mapping differences in consumer perception of 
sharp Cheddar cheese in the United States. J. Food Sci. 74:S276S285.

Escuder-Gilabert, L., and M. Peris. 2010. Review: Highlights in recent applications of electronic tongues in food analysis. Anal. Chim. Acta 665:15-25.

Fenelon, M. A., and T. P. Guinee. 2000. Primary proteolysis and textural changes during ripening in Cheddar cheeses manufactured to different fat contents. Int. Dairy J. 10:151-158.

Folch, J., M. Lees, and G. H. S. Stanley. 1957. A simple method for the isolation and purification of total lipids from animal tissues. J. Biol. Chem. 226:497-509.

Guinee, T. P., E. O. Mulholland, J. Kelly, and D. J. O. Callaghan. 2007. Effect of protein-to-fat ratio of milk on the composition, manufacturing efficiency, and yield of cheddar cheese. J. Dairy Sci. 90:110-123.

Hruskar, M., N. Major, M. Krpan, I. Panjkota Krbavcic, G. Saric K. Markovic, and N. Vahcic. 2009. Evaluation of milk and dairy products by electronic tongue. Mljekarstvo 59:193-200.

Iwasawa, A., A. Suzuki-Iwashima, F. Iida, and M. Shiota. 2014. Effects of flavor and texture on the desirability of Cheddar cheese during ripening. Food Sci. Technol. Res. 20:23-29.

Kalit, M. T., K. Markovic, S. Kalit, N. Vahcic, and J. Havranek. 2014 Application of electronic nose and electronic tongue in the dairy industry. Mljekarstvo 64:228-244.

Latha, R. S., and P. K. Lakshmi. 2012. Electronic tongue: an analytical gustatory tool. J. Adv. Pharm. Technol. Res. 3:3-8.

Li, S., C. Ma, Z. Liu, G. Gong, Z. Xu, A. Xu, and B. Hua. 2014. Flavour analysis of stirred yoghurt with Cheddar cheese adding into milk. Food Sci. Technol. Res. 20:939-946.

Moser, E. B. 2004. Repeated measures modeling with PROC MIXED. Statistics and Data Analysis, SUGI 29 Technical Proceedings, SAS Institute. 29:1-19.

Newman, J., T. Egan, N. Harbourne, D. O'Riordan, J. C. Jacquier, and M. O'Sullivan. 2014a. Correlation of sensory bitterness in dairy protein hydrolysates: Comparison of prediction models built using sensory, chromatographic and electronic tongue data. Talanta 126:46-53

Newman, J., N. Harbourne, D. O'Riordan, J. C. Jacquier, and M. O'Sullivan. 2014b. Comparison of a trained sensory panel and an electronic tongue in the assessment of bitter dairy protein hydrolysates. J. Food Eng. 128:127-131.

R Core Team. 2017. R: A language and environment for statistical computing. R Foundation for Statistical Computing, Vienna, Austria. https://www.R-project.org/.

Rattray, W., and P. Jelen. 1996. Protein standardization of milk and dairy products. Trends Food Sci. Technol. 7:227-234.

Rogers, N. R., M. A. Drake, C. R. Daubert, D. J. McMahon, T. K. Bletsch, and E. A. Foegeding. 2009. The effect of aging on lowfat, reduced-fat, and full-fat Cheddar cheese texture. J. Dairy Sci 92:4756-4772.

Singh, T. K., and K. R. Cadwallader. 2008. Cheese. Pages 273-308 in Dairy Processing and Quality Assurance. 1st ed. R. C. Chandan, A. Kilara, and N. P. Shah, ed. Wiley-Blackwell, Danvers, MA.

Singh, T. K., M. Drake, and K. R. Cadwallader. 2003. Flavor of Cheddar cheese: A chemical and sensory perspective. Compr. Rev. Food Sci. Food Saf. 2:139-162.

Steury, T. 2013. How Washington tastes: The apple meets Cougar Gold. Pages 20-37 in Washington State magazine. Vol. 12. Washington State University, Pullman.

Wehr, M. H., and J. F. Frank, ed. 2004. Standard Methods for the Examination of Dairy Products. 17th ed. Am. Pub. Health Assoc. Inc., Washington, DC

Yang, B., and Z. Vickers. 2004. Optimatization of Cheddar cheese taste in model cheese systems. J. Food Sci. 60:229-236.

Young, N. D., M. Drake, K. Lopetcharat, and M. R. McDaniel. 2004. Preference mapping of Cheddar cheese with varying maturity levels. J. Dairy Sci. 87:11-19. 